\title{
Quality assessment of integrated water vapour measurements at the St. Petersburg site, Russia: FTIR vs. MW and GPS techniques
}

\author{
Yana A. Virolainen ${ }^{1}$, Yury M. Timofeyev ${ }^{1}$, Vladimir S. Kostsov ${ }^{1}$, Dmitry V. Ionov $^{1}$, Vladislav V. Kalinnikov ${ }^{2}$, \\ Maria V. Makarova ${ }^{1}$, Anatoly V. Poberovsky ${ }^{1}$, Nikita A. Zaitsev ${ }^{1}$, Hamud H. Imhasin ${ }^{1}$, Alexander V. Polyakov ${ }^{1}$, \\ Matthias Schneider $^{3}$, Frank Hase ${ }^{3}$, Sabine Barthlott ${ }^{3}$, and Thomas Blumenstock ${ }^{3}$ \\ ${ }^{1}$ Atmospheric Physics Department, St. Petersburg State University, Saint Petersburg, 199034, Russia \\ ${ }^{2}$ Kazan (Volga Region) Federal University, 420008, Kazan, Russia \\ ${ }^{3}$ Institute of Meteorology and Climate Research (IMK-ASF), Karlsruhe Institute of Technology, Karlsruhe, Germany \\ Correspondence to: Yana A. Virolainen (yana.virolainen@ spbu.ru) and M. Schneider (matthias.schneider@kit.edu)
}

Received: 30 April 2017 - Discussion started: 29 May 2017

Revised: 22 September 2017 - Accepted: 27 September 2017 - Published: 22 November 2017

\begin{abstract}
The cross-comparison of different techniques for atmospheric integrated water vapour (IWV) measurements is the essential part of their quality assessment protocol. We inter-compare the synchronised data sets of IWV values measured by the Bruker 125 HR Fourier-transform infrared spectrometer (FTIR), RPG-HATPRO microwave radiometer (MW), and Novatel ProPak-V3 global navigation satellite system receiver (GPS) at the St. Petersburg site between August 2014 and October 2016. As the result of accurate spatial and temporal matching of different IWV measurements, all three techniques agree well with each other except for small IWV values. We show that GPS and MW data quality depends on the atmospheric conditions; in dry atmosphere (IWV smaller than $6 \mathrm{~mm}$ ), these techniques are less reliable at the St. Petersburg site than the FTIR method. We evaluate the upper bound of statistical measurement errors for clear-sky conditions as $0.29 \pm 0.02 \mathrm{~mm}(1.6 \pm 0.3 \%), 0.55 \pm 0.02 \mathrm{~mm}$ $(4.7 \pm 0.4 \%)$, and $0.76 \pm 0.04 \mathrm{~mm}(6.3 \pm 0.8 \%)$ for FTIR, GPS, and MW methods, respectively. We propose the use of FTIR as a reference method under clear-sky conditions since it is reliable on all scales of IWV variability.
\end{abstract}

\section{Introduction}

Water vapour is one of the most important greenhouse gases in the Earth's atmosphere. Its contribution to the natural greenhouse effect is rather variable, accounting for about
$70 \%$ in clear-sky conditions (Kiehl and Trenberth, 1997). Water vapour plays a key role in different chemical processes in the atmosphere, in tropospheric dynamics, in transferring the latent heat and, additionally, it is an essential part of the global hydrological cycle (IPCC, 2007). In recent years, a number of studies reported the presence of long-term trends of water vapour content in different atmospheric layers (Oltmans et al., 2000; Trenberth et al., 2005; Nilsson et al., 2008; Mieruch et al., 2008; Hegglin et al., 2014). The observed climate warming brings forward an increase in integrated water vapour (IWV), which in turn forces further climate change (Dai et al., 2001).

The importance of water vapour stimulates monitoring of its content at all temporal and spatial scales with various in situ and remote sensing methods. The requirements defined for the accuracy of IWV retrieval depend on the particular meteorological or climatological application area (http://www.wmo-sat.info/oscar/requirements). Thus, for example, for numerical weather prediction and very shortrange forecasts, requirements for uncertainty of measured IWV values vary from $1 \mathrm{~mm}$ (goal) to $5 \mathrm{~mm}$ (threshold). The "threshold" is the minimum requirement to ensure that the data are useful, and the "goal" is the ideal requirement above. Sometimes, these requirements are defined in relative units: statistical errors of IWV retrieval ought to have a value of $0.5-2.0 \%$, and total errors should have a value of $1-3 \%$. None of the existing systems for IWV measurements meets all goal requirements in terms of uncertainty, horizontal resolution, observing cycle, and timeliness. This leads to the ne- 
cessity of using various methods and instruments and, consequently, fosters different programs of inter-comparison of IWV measurements with the aim of calibrating them and assessing their accuracy. The latter is a part of the protocol for assimilation of different measurements and numerical model data. The significant spatial (at 1-2 km scale) and temporal (at $1 \mathrm{~h}$ scale) variations of IWV aggravate the problem of inter-comparison of various methods as well as their different spatial resolution, which is often evaluated only at a qualitative level.

Recently, a number of programs devoted to the intercomparison of different methods for IWV retrieval have been performed in various geographical regions (see, for example, Palm et al., 2010; Schneider et al., 2010a; Vogelmann et al., 2011; Buehler et al., 2012; Weaver et al., 2017). The special ESA project (http://globvapour.info) was aimed at generating validated long-term satellite IWV data sets with error assessments. A book edited by Kaempfer (2013) collects results of various campaigns for ground-based water vapour retrieval. Navas-Guzman et al. (2014), Perez-Ramirez et al. (2014), and Reagan et al. (1995) presented the typical examples of IWV inter-comparison as well. Several studies have been performed in Russia recently: an inter-comparison of IWV retrieval techniques from airborne, satellite, and groundbased measurements at Tomsk (Makarova et al., 2014); and a series of IWV comparisons by different methods at Peterhof (Semenov et al., 2015; Berezin et al., 2016, 2017; Virolainen et al., 2016; Ionov et al., 2017).

In this study, we focus on the Fourier-transform infrared (FTIR) technique for IWV retrieval and on the data from the Bruker 125 HR spectrometer - the only instrument of such type in Russia that is certified by the Infrared Working Group (IRWG) of the Network for the Detection of Atmospheric Composition Change (NDACC). We analyse different types of FTIR retrievals, calculate their error budget, and propose a simple method for harmonisation of IWV values measured in different spectral regions with the aim of extending the continuous data set of FTIR measurements. Afterward, we compare FTIR data with independent simultaneous measurements of the RPG-HATPRO microwave radiometer (MW) and the Novatel ProPak-V3 global navigation satellite system receiver (GPS) at the St. Petersburg site, analyse the obtained differences under various atmospheric conditions, and finally evaluate the empirical errors of considered techniques for IWV retrievals, giving the conclusions and recommendations for their usage.

In Sect. 2, we introduce the St. Petersburg site for atmospheric monitoring, describe different instruments and techniques for IWV retrieval, present in detail the FTIR IWV measurements, and assess and overview the error budget of considered instrumentation and techniques. In Sect. 3, we analyse two different types of FTIR IWV retrieval, intercompare triplets of simultaneous IWV measurements by the FTIR, GPS, and MW techniques, and empirically assess the precision of studied methods. In Sect. 4, we briefly review

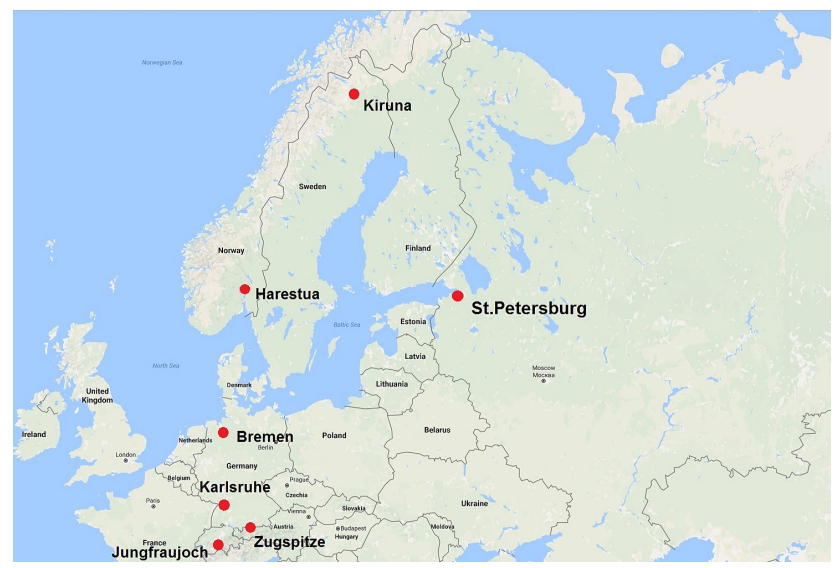

Figure 1. Location of NDACC IRWG sites in Europe (red circles).

previous studies on cross-comparison of various IWV methods; Sect. 5 summarises the most important results and conclusions of the current research.

\section{Observational facilities at the St. Petersburg site}

The St. Petersburg site of Saint Petersburg State University ( $\mathrm{SPbU}$ ) is located in a suburb of St. Petersburg (Peterhof) approximately $35 \mathrm{~km}$ west-southwest from the city centre at $59^{\circ} 53^{\prime} \mathrm{N}, 29^{\circ} 50^{\prime} \mathrm{E} ; 20 \mathrm{~m}$ a.s.l. (indicated in Fig. 1 by red circle together with other European NDACC IRWG sites).

The climate of Saint Petersburg is humid continental (Dfb-Köppen climate classification) with moderately mild winters and moderately warm summers. Weather is highly variable with frequent air-mass changes: approximately 165 overcast days and 140 days of cyclone activity per year. Timofeyev et al. (2016) presents a short description of the site, its instrumentation, and some results of FTIR retrievals. In 2016, the St. Petersburg site joined the IRWG-NDACC community with its FTIR system.

In recent years, the IWV content has been regularly measured at the St. Petersburg site (Semenov et al., 2015; Berezin et al., 2016, 2017; Virolainen et al., 2016; Ionov et al., 2017). Table 1 presents a description and main results of different campaigns for IWV inter-comparisons at Peterhof and gives the references to the original studies. Note that all series correspond to different rather short time intervals as well as to various numerical estimates; this makes their comparison difficult. Therefore, it is worth inter-comparing all available simultaneous IWV measurements at the St. Petersburg site throughout the longest available period to assess the quality of individual methods, which is the subject of the current research.

Following Semenov et al. (2015) and Berezin et al. (2016, 2017), who demonstrated that the $50 \mathrm{~km}$ distance between locations of IWV measurements might be responsible for significant disagreement due to the spatial inhomogeneity of 
Table 1. The IWV comparison campaigns at the St. Petersburg site, involving the data of FTIR, GPS, Cimel sun photometer, and radiosonde (RS) measurements. Mean is the mean difference; SD is the standard deviation of mean difference.

\begin{tabular}{llrrl}
\hline Pairs & Period & Mean \pm SD, mm $(\%)$ & Correlation coefficient & Reference \\
\hline FTIR-RS & Apr 2009-Mar 2012 & $-0.06 \pm 2.34(-1.7 \pm 22.1)$ & $0.961 \pm 0.007$ & Semenov et al. (2015) \\
RS-MW & Mar 2013-May 2014 & $-0.31 \pm 3.13(-2.2 \pm 22.1)$ & $0.934 \pm 0.004$ & Berezin et al. (2016) \\
MW-FTIR & Mar 2013-Jun 2015 & $0.29 \pm 0.42(2.8 \pm 4.1)$ & $0.9982 \pm 0.0001$ & Virolainen et al. (2016) \\
\hline MW-Cimel & Mar 2013 & $1.56 \pm 1.07(10.9 \pm 7.4)$ & $0.9962 \pm 0.0001$ & \\
FTIR-Cimel & - & $1.11 \pm 0.94(10.1 \pm 8.6)$ & $0.9952 \pm 0.0003$ & Berezin et al. (2017) \\
RS-Cimel & May 2015 & $-0.5 \pm 2.6(-4 \pm 19)$ & $0.944 \pm 0.005$ & \\
\hline MW-GPS & Sep 2014 & $-0.3 \pm 0.6(-3 \pm 9)$ & $0.997 \pm 0.001$ & \\
FTIR-MW & - & $-0.4 \pm 0.4(-7 \pm 8)$ & $0.995 \pm 0.002$ & Ionov et al. (2017) \\
FTIR-GPS & Sep 2015 & $-0.5 \pm 0.6(-6 \pm 11)$ & $0.998 \pm 0.002$ & \\
\hline
\end{tabular}

the water vapour fields, we exclude from the current study the radiosonde data of nearby WMO site no. 26063 (Voejkovo). Moreover, in the comparison we do not include the sun photometer (Cimel) measurements since they require an additional calibration procedure (Berezin et al., 2017). Therefore, the current research is devoted to the simultaneous IWV measurements by three ground-based methods that use the Bruker 125 HR spectrometer (FTIR), RPG-HATPRO radiometer (MW), and global navigation satellite system receiver Novatel ProPak-V3 (GPS).

\subsection{FTIR method}

Since the beginning of 2009 , the St. Petersburg site FTIR system, which consists of a Bruker 125 HR spectrometer and a in-house-designed solar tracker (Poberovsky, 2010), has been recording solar spectra. Atmospheric FTIR measurements using the Sun as a light source are performed under cloudless conditions or when breaks in cloud cover allow measurements of solar spectra. The alignment of the FTIR instrument is controlled by $\mathrm{HBr}$ cell spectra generated using both an internal light source and the Sun (Hase, 2012; Makarova et al., 2016).

We analyse the measured spectra with the PROFFIT software (Hase et al., 2004), which consists of a precise lineby-line radiative transfer model and an adaptable inversion algorithm. The latter supports different retrieval approaches (e.g. optimal estimation, Tikhonov-Phillips, use of logarithmised mixing ratios in the state vector, inter-species constraints for work on isotopologues). This software is routinely used at a number of NDACC sites (Kiruna, Sweden; Izaña, Spain; Altzomoni, Mexico). In this study, we retrieve IWV from measurements in two different spectral regions: 1098-1222 $\mathrm{cm}^{-1}$ (type A) and $2610-3020 \mathrm{~cm}^{-1}$ (type M). Type A is a standard PROFFIT retrieval scheme; type M refers to the MUSICA 2015 retrieval scheme (Barthlott et al., 2017) and has a special focus on $\left\{\mathrm{H}_{2}^{16} \mathrm{O}, \mathrm{HD}^{16} \mathrm{O} / \mathrm{H}_{2}^{16} \mathrm{O}\right\}$ data pairs.
Figure 2 presents typical ground-based IFS Bruker 125HR measurements of solar absorption spectra in the fitted spectral microwindows containing water vapour lines. FTIR measurements are performed with a spectral resolution of about $0.005 \mathrm{~cm}^{-1}$ (with optical path difference of $180 \mathrm{~cm}$ ). The Atype spectral region is characterised by the saturated water vapour lines (with the $\mathrm{H}_{2}^{16} \mathrm{O}$ isotopologue having stronger signatures than the $\mathrm{HD}^{16} \mathrm{O}$ isotopologue) and their interference with $\mathrm{O}_{3}$ absorption lines, whereas water vapour lines in the M-type region are of very similar line strengths for $\mathrm{H}_{2}^{16} \mathrm{O}$ and $\mathrm{HD}^{16} \mathrm{O}$ and not saturated but well isolated from other absorption lines. The spectral scheme for M-type retrieval also includes three microwindows with $\mathrm{CO}_{2}$ lines (in 2610 $2627 \mathrm{~cm}^{-1}$ spectral range), which are used for temperature retrieval.

To improve the IWV measurement accuracy we use approaches proposed in Schneider et al. (2010b): (a) a logarithmic scale inversion, (b) a speed-dependent Voigt line-shape model, (c) the consideration of atmospheric emission for the retrievals, (d) a simultaneous retrieval of interfering species, and finally, for the M-type retrievals, (e) a simultaneous temperature retrieval as well as the use of water vapour isotopologue inter-species constraints (Barthlott et al., 2017). The $\mathrm{H}_{2}^{16} \mathrm{O}$ and $\mathrm{HD}^{16} \mathrm{O}$ retrievals in the A-type setup are made independently. For spectroscopic parameters of the absorption lines, we use the HITRAN2008 database with 2009 updates (Rothman et al., 2009) with slight modifications of pressure broadening and line intensities - for the spectral range used by the A-type retrieval, according to Schneider et al. (2011); and for spectral range used by the M-type retrieval, according to the Appendix of Barthlott et al. (2017).

The corresponding pressure and temperature profiles used for the analysis are the daily National Centers for Environmental Prediction (NCEP) re-analysis data (ftp://acd.gsfc. nasa.gov/pub/ftpmet/profiles/PET) for the Peterhof location. The a priori profiles of interfering atmospheric constituents are adopted from The Whole Atmosphere Community Climate Model (WACCM) data - using a single set of climatological a priori profiles during all seasons for the Peterhof lo- 

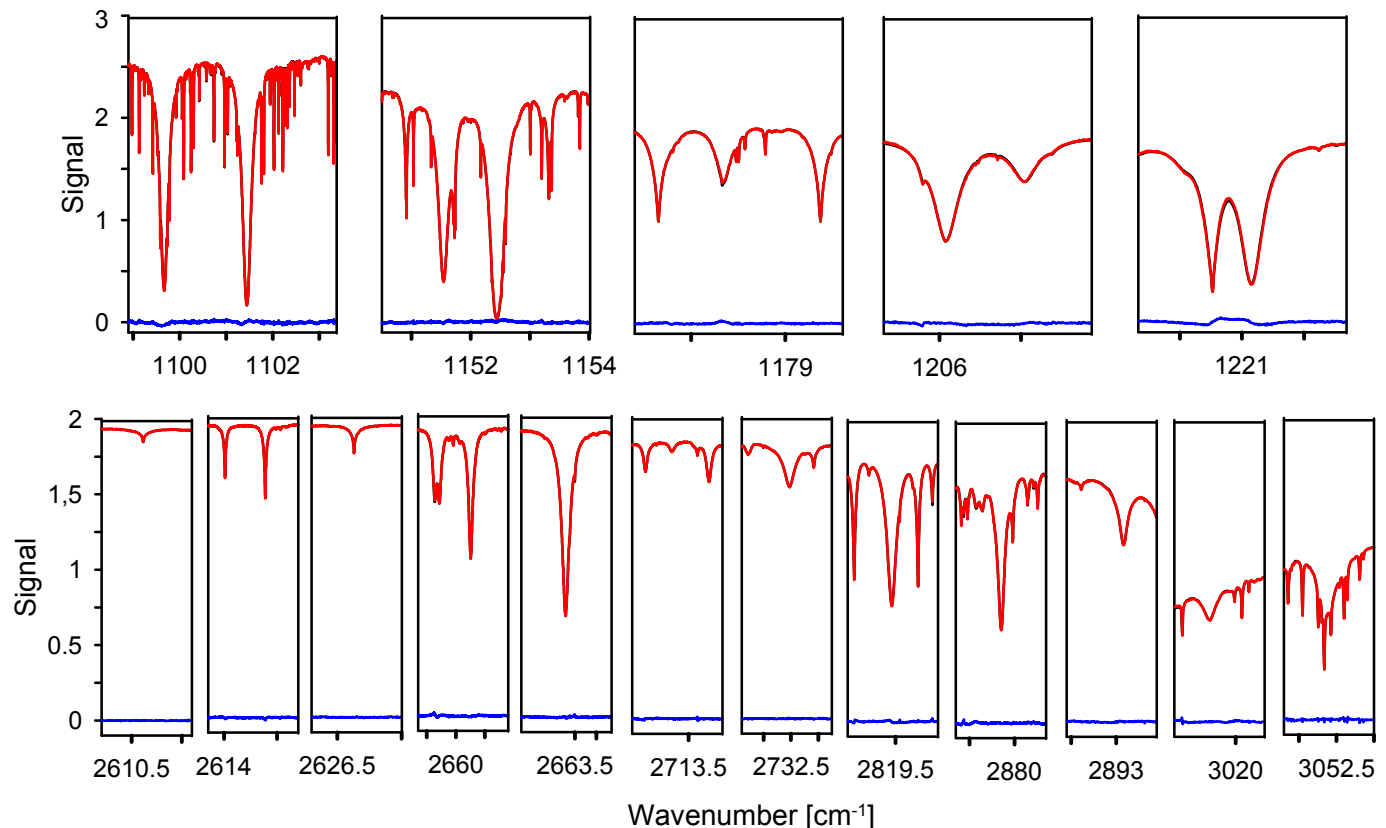

Figure 2. The A-type (above) and M-type (below) spectral microwindows taken from spectra measured on 7 May 2016. Red lines: measured spectra; black lines: simulated spectra; blue lines: residuals (difference between measurement and simulation). IWV content equals 8 mm; solar elevation angle is $47.1^{\circ}$.

cation (Park et al., 2013). The selected mode of the PROFFIT retrieval code is based on the Tikhonov-Phillips approach (A type) (Tikhonov, 1963; Phillips, 1962) and on the optimal estimation method (M type) (Rodgers, 2000), respectively. After analysis of spectra, we filtered the IWV retrievals, depending on the ratio: remaining measurement noise (in percent) to the number of degrees of freedom for signal. Further, we consider only those retrievals for which this ratio is less than 1.0 for the A-type and 0.5 for the M-type retrievals. We chose this criterion in accordance with the signal-to-noise ratio in corresponding spectral regions, trying to optimise the number of less noisy measurements that represent all atmospheric conditions. Thus, for the period between March 2009 and December 2016 we selected 3265 and 3548 IWV retrievals of A type and $\mathrm{M}$ type, respectively.

For the error budget calculations, we assume the same uncertainty sources and values for both types of the retrieval. We calculate "gain matrices" that show the sensitivity of the retrieval to some error source, and associated covariance matrices for statistical and systematic errors (Rodgers, 2000). For calculating the error matrices, the uncertainty of the error sources are taken into account as listed in Table 2. The relative weight of statistical and systematic contribution to the total IWV error varies depending on the error source (Hase et al., 2004). The spectroscopic line parameters' uncertainty (see Table 2) is the major source of systematic errors. In the A-type spectral channels (see Fig. 2) the intensity of solar radiation is smaller than in the M-type channels, resulting in a decrease in the signal-to-noise ratio and, consequently, in an increase in measurement noise and its influence on statistical errors of the A-type retrieval. Statistical errors of the A-type retrieval are controlled mainly by temperature profile uncertainty, whereas in the M-type scheme the temperature profile is simultaneously retrieved together with the target gases. Thus, our estimations indicate that IWV retrieval of the $\mathrm{M}$ type is slightly more precise than that of the A type due to (a) the higher signal-to-noise ratio and (b) the simultaneous temperature retrieval.

\subsection{MW method}

The 14-channel microwave radiometer RPG-HATPRO (third generation) is one of the instruments used for IWV measurements at the St. Petersburg site. It has been functioning since June 2012 in constant mode with a sampling interval of about 1-2 s and an integration time of $1 \mathrm{~s}$. A complete description of radiometers of the RPG-HATPRO type is presented at the website of the manufacturer (http://www. radiometer-physics.de). All information relevant to the experimental setup can be found in the paper by Kostsov et al. (2016). It should be noted that IWV measurements are performed from zenith observations only.

We analyse the atmospheric MW radiation brightness temperature spectra using two separate and independent retrieval algorithms. The first algorithm is the built-in regression algorithm (REGR) provided by the manufacturer and tuned for the $\mathrm{SPbU}$ measurement site. The algorithm uses a quadratic regression scheme applied to the brightness temperature ob- 
Table 2. Error budget of IWV retrieval by the FTIR technique.

\begin{tabular}{|c|c|c|c|c|c|}
\hline \multirow[t]{2}{*}{ Error source } & \multirow[t]{2}{*}{ Uncertainty } & \multicolumn{2}{|c|}{ A-type errors, $\%$} & \multicolumn{2}{|c|}{ M-type errors, $\%$} \\
\hline & & Statistical & Systematic & Statistical & Systematic \\
\hline Baseline (offset and channelling) & $0.1 \%$ and $0.2 \%$ & 0.3 & 0.3 & 0.3 & 0.3 \\
\hline $\begin{array}{l}\text { Instrumental line shape (modula- } \\
\text { tion efficiency and phase error) }\end{array}$ & $1 \%$ and $0.01 \mathrm{rad}$ & 0.08 & 0.08 & 0.06 & 0.06 \\
\hline Temperature profile & $\begin{array}{l}1^{\circ} \mathrm{K} \text { (surface- } 10 \mathrm{~km} \text { a.s.1.) } \\
2^{\circ} \mathrm{K}(10-35 \mathrm{~km} \text { a.s.1.) } \\
5^{\circ} \mathrm{K} \text { (above } 35 \mathrm{~km} \text { a.s.1.) }\end{array}$ & 0.8 & 0.3 & 0.04 & 0.02 \\
\hline Spectroscopy $(S$ and $\gamma)$ & $2 \%$ and $2 \%$ & - & 2.2 & - & 2.0 \\
\hline Measurement noise & From residuals & 0.2 & - & 0.1 & - \\
\hline Total error, \% & & $0.9 \pm 0.3$ & $2.3 \pm 0.3$ & $0.4 \pm 0.2$ & $2.0 \pm 0.2$ \\
\hline
\end{tabular}

servations in zenith mode plus surface pressure sensor data. Tuning of this algorithm is based on radiative transfer calculations for atmospheric models that have been compiled using 10 years of radio-sounding data at the Voejkovo station near St. Petersburg. The absolute accuracy of IWV retrievals by the REGR declared by the manufacturer is $0.3 \mathrm{~mm}$; the random noise is less than $0.05 \mathrm{~mm}$. Our estimates of IWV variations in stable atmospheric conditions for different days of measurements (Virolainen et al., 2016) showed that the standard deviation (SD) of means for RPG-HATPRO equals $0.05-0.09 \mathrm{~mm}$, which is rather close to noise level presented by other researchers (Steinke et al., 2015).

The second algorithm is based on the inversion of the radiative transfer equation and therefore is referred to below as a "physical algorithm" (PHYS). This algorithm uses the well-known and widely applied approach of simultaneous retrieval of several atmospheric parameters profiles, which influence the radiative transfer at frequencies corresponding to spectral channels of the MW radiometer. Since the problem is ill-posed, we used the optimal estimation method for its regularisation. The description of the specific features of the physical algorithm applied to RPG-HATPRO measurements, the assessment of the retrieval accuracy for different parameters, and the examples of retrievals can be found in the paper by Kostsov (2015a). In addition to the brightness temperature measurements, PHYS utilises the surface pressure, temperature, and humidity readings; the temperature and relative humidity profile statistics; and the hydrostatic equilibrium constraint by applying the general approach to the solution of multi-parameter inverse problems (Kostsov, 2015b). To calculate the IWV values, we integrate the absolute humidity vertical profile. We obtain the IWV retrieval error from the error matrix corresponding to the absolute humidity profile, which we calculate for every single set of brightness temperature measurements. Therefore, the IWV retrieval error estimate is a variable quantity. In practice, the values of statistical retrieval error estimates for PHYS are within the interval $0.08-0.10 \mathrm{~mm}$.
The MW IWV retrievals at the St. Petersburg site considered in earlier studies (Berezin et al., 2016, 2017; Virolainen et al., 2016; Ionov et al., 2017) correspond to the REGR. In this study, we use PHYS to analyse the MW-measured spectra due to the following reasons: (a) PHYS provides the error estimates for every single retrieval together with a quality control flag, which is very useful for detection and removal of spurious data; (b) the output of PHYS is a self-consistent set of several atmospheric parameters (water vapour and temperature profiles, pressure profile, and cloud liquid water content); and (c) PHYS is a flexible tool that gives the possibility to use different amounts of input data and it is more convenient for modifications, if necessary.

We compared the results of the REGR and PHYS retrieval algorithms throughout the whole period of measurements (2012-2016) to assess the differences in retrieved IWV values. Relative mean difference of the two data sets does not depend on absolute IWV values: REGR is biased high compared to PHYS by approximately $5 \%$, which means that there is a factor of 1.05 between the two retrieval techniques. Almost a half of the absolute differences (PHYS vs. REGR) are between -0.6 and $-0.2 \mathrm{~mm}$. The mean difference between two data sets amounts to $-0.52 \mathrm{~mm}$ with an SD of $0.44 \mathrm{~mm}$. The two retrievals are less consistent in a dry atmosphere. The RPG-HATPRO radiometer is operating at its limits below $5 \mathrm{~mm}$ of IWV, which is affected by the intrinsic relative weakness of the $22 \mathrm{GHz}$ water vapour line. Therefore, the errors of both methods increase with decreasing IWV values in dry conditions. Differences in the IWV results of the two algorithms might be due to many reasons, but particularly due to different a priori information, radiative transfer model, etc.

\subsection{GPS method}

The GPS method implies a technique of active remote sensing by GPS satellites, which transmit radio signals in the microwave range. Before these signals can reach the Earthbased receiver, they are delayed and refracted in the atmosphere. Owing to the permanent dipole moment of water 
vapour molecules, atmospheric refractivity is very sensitive to the presence of this gaseous constituent in the atmosphere (Businger et al., 1996). Since a hydrogen bond between water molecules in liquid water and ice significantly reduces the contribution of the dipole moment to radio signal delay, the impact of cloud water and ice on atmospheric refractivity is limited. This allows ground-based GPS receivers to provide data on IWV above the receiver site even in cloudy weather. If the position of the receiver is accurately known, a target atmospheric delay is derived by comparison between an observed signal path length (pseudorange) and a geometric distance between satellite and receiver (true range).

For IWV retrieval, we use a ground-based GPS sensor - Novatel ProPak-V3 dual-frequency receiver with a GPS702-GG antenna mounted on a roof. The instrument has been operating continuously in all weather conditions since August 2014. The carrier phase and binary code pseudorange measurements from GPS satellites on two GPS carrier frequencies $(1227$ and $1575 \mathrm{MHz})$ are processed with the help of TropoGNSS software, developed at Kazan Federal University (Kalinnikov and Khutorova, 2017). The retrieval algorithm identifies the precise point positioning strategy for zenith tropospheric delay (ZTD) estimation (Kouba, 2015). Phase measurements play a key role in the algorithm: they are compared with geometric distances between receiver and corresponding satellites. Code measurements serve only for calculation of receiver clock corrections. Geometric distances and satellite clock corrections are determined using precise ephemerides/clock products of the International GNSS Service (http://www.igs.org). The algorithm takes into account changes in the receiver antenna's position due to the ocean loading effect, as well as solid and pole tides (Petit and Luzum, 2010). The influence of the ionosphere is excluded by the formation of the iono-free combination of phase measurements at two frequencies (Schaer, 1999). Each phase measurement contains an unknown constant number of radio-wave cycles between receiver and satellites. This constant called "phase ambiguity" is removed by taking the differences between phase measurements from two consecutive epochs. Slant tropospheric delays during measurements are expressed in the form of multiplication of the zenith tropospheric delay and Niell mapping function that are determined by the zenith angle of each satellite, day of a year, and latitude and altitude of station (Niell, 1996). The zenith cut-off angle in TropoGNSS processing is established at $83^{\circ}$. Time series of iono-free combinations of phase measurements are consistently processed from epoch to epoch using a Kalman filter with ZTD as an unknown parameter. Output ZTD time series have a $5 \mathrm{~min}$ step. We assume that ZTD is a sum of the dry hydrostatic (ZHD) and the wet (ZWD) components (Bevis et al., 1992). The hydrostatic component with the accuracy of $1 \mathrm{~mm}$ is determined using the Saastamoinen model (Saastamoinen, 1973). The wet component is defined as a difference between ZTD and ZHD and is then converted to IWV values following an approach proposed by Askne and Nordius (1987) and Mendes (1999).

The uncertainty of ZHD and ZWD determination results in an IWV retrieval uncertainty of $1.5-2 \mathrm{~mm}$. This estimate is close to the uncertainty of GPS IWV measurements obtained by other authors. Ning et al. (2016) reported an uncertainty of IWV measurements of around $0.5-1.0 \mathrm{~mm}$; Steinke et al. (2015) presented an uncertainty of GPS IWV measurements of about 1-2 mm. Ionov et al. (2017) assessed the errors of various methods of IWV retrieval at the St. Petersburg site by analysing the differences in simultaneous IWV retrievals and got the following estimates: the statistical error of FTIR and MW measurements was $0.3 \mathrm{~mm}$, while that for the GPS technique was $0.5 \mathrm{~mm}$.

The variability of presented errors of IWV measurements can be explained by the dependence of retrieval errors on the atmospheric state - particularly, the IWV values, measurement conditions (solar zenith angles, number of used satellites, etc.), the stability of the instruments, and the consistency of the measurements themselves. Taking into account the location of the St. Petersburg site between the Gulf of Finland and rural areas, the local horizontal gradient of water vapour distribution might also be a reason for differences.

\section{IWV measurements at the St. Petersburg site}

All instruments for IWV monitoring are installed at the buildings of the SPbU Peterhof campus: the RPG-HATPRO radiometer and Novatel ProPak-V3 receiver were installed on the roof of the same building (at a distance of $2 \mathrm{~m}$ ), 55 ma.s.l.; the Bruker 125 HR spectrometer was installed in the ground floor of a nearby building at a distance of $330 \mathrm{~m}$ to the west, $21 \mathrm{~m}$ a.s.l. Figure 3 depicts schematically a diagram of the mutual location of all three instruments. It is worth mentioning that the solar tracking system of Bruker $125 \mathrm{HR}$ is located on a roof, so the beam path partly passes through a pipe from the top of the building to the ground floor. In accordance with the beam pattern of the MW radiometer, the input signal comes from about $20 \mathrm{~m}$ above the instrument. We evaluated possible differences in measured IWV values due to differences in elevation of the considered instrumentation. We used the ECMWF monthly averaged humidity profiles and got the following estimates. Depending on season, the FTIR technique might give values $0.1-0.4 \mathrm{~mm}$ and $0.2-$ $0.5 \mathrm{~mm}$ higher than the GPS and MW techniques, respectively. The difference between GPS and MW might reach $0.1-0.2 \mathrm{~mm}$.

Although the MW radiometer and GPS receiver are located close to each other, they have some spatial disagreement: the MW radiometer is operated only in a zenith observation mode for IWV measurements, whereas the GPS receiver gets the information from various satellites with a horizontal averaging of several dozen of kilometres. We also should take into account the difference in observed air 


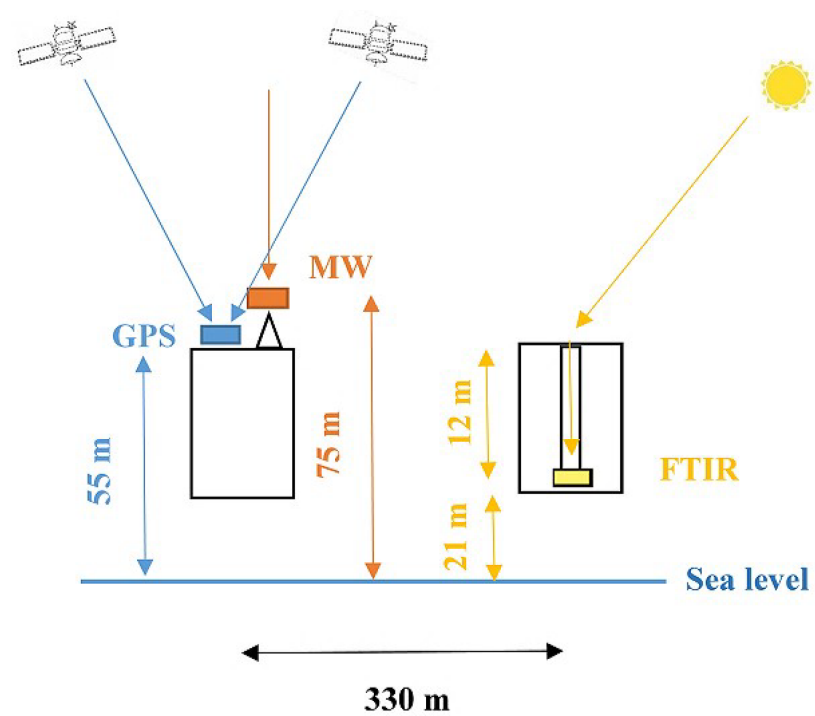

Figure 3. Schematic location of FTIR, MW, and GPS instrumentation at the St. Petersburg site.

masses while comparing MW and FTIR measurements. Virolainen et al. (2016) have demonstrated that, depending on season and time of the day (different solar azimuth and zenith angles), the measured IWV values may belong to different air masses located at a distance of up to $20-25 \mathrm{~km}$. At worst, the spatial inhomogeneity of water vapour fields might cause the discrepancy between two types of measurements, especially considering the surroundings of the St. Petersburg site - the Gulf of Finland on one side and the rural suburbs of Saint Petersburg on the other.

The MW radiometer measures spectra every $2 \mathrm{~s}$; the GPS receiver performs a single measurement every $5 \mathrm{~min}$; the FTIR spectrometer records spectra only in clear-sky conditions, with one record usually lasting about $12 \mathrm{~min}$. Table 3 lists the main features of considered instrumentation for IWV measurements. It is worth mentioning that the period of observations of all three instruments varies from device to device: the FTIR has been operational since January 2009, the MW radiometer since June 2012, and the GPS receiver since August 2014. There are also some gaps in measurement series due to technical problems with one or more instruments. In order to synchronise all three types of IWV measurements, we average MW and GPS measurements over a 12 min interval for each FTIR individual measurement. In this study, we consider the period of IWV measurements from September 2014 to December 2016 when such triplets are available.

\subsection{FTIR measurements}

In earlier papers (Semenov et al., 2015; Virolainen et al., 2016; Berezin et al., 2017; Ionov et al., 2017), we presented the results of FTIR IWV retrievals that used the spectral scheme close to the A type. In this study, we add the M-

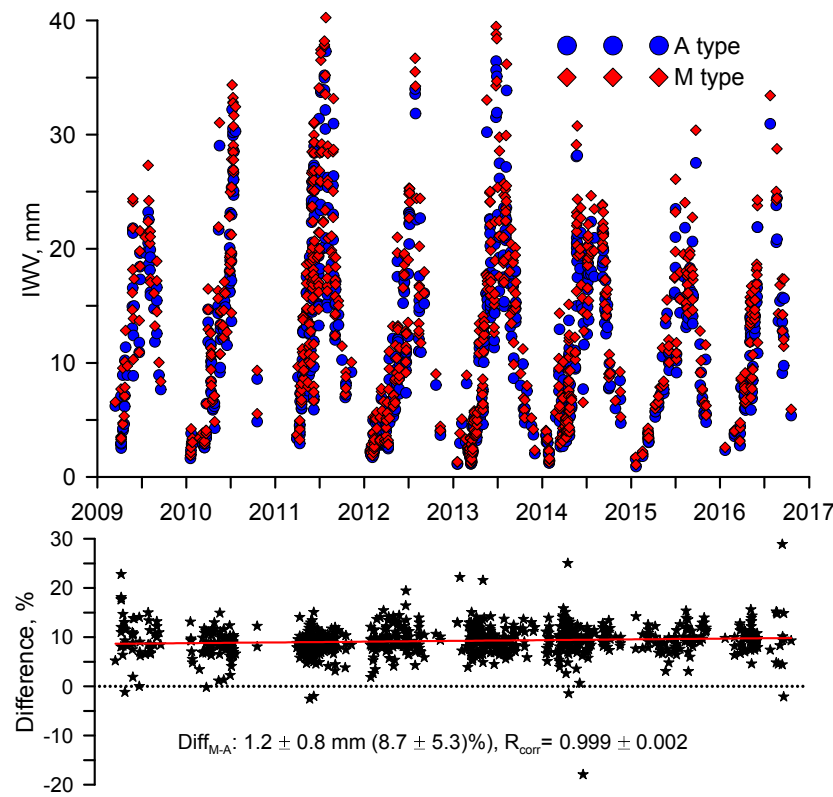

Figure 4. Time series of IWV measurements (above) using the FTIR method: the A type (blue circles) and M type (red diamonds) and their relative difference (below). Red line indicates a time dependence of differences approximated by a linear regression line.

type retrieval developed for the MUSICA project (Schneider et al., 2016; Barthlott et al., 2017). Therefore, we compare FTIR IWV retrievals of these two setups to harmonise our previous and present results.

Since we record solar spectra within limited spectral bands using a set of broadband filters, the spectra underlying the Atype and M-type retrievals are not observed simultaneously. The acquisition time for individual interferograms obtained by co-adding 10 scans equals approximately $12 \mathrm{~min}$. We usually make a series of three individual measurements for each spectral band. Thus, there is a time lag between the two types of FTIR IWV measurements of at least $12-15 \mathrm{~min}$.

In order to compare data sets of the A-type and M-type IWV measurements, we assume the pairs to be near synchronised if the time mismatch between the nearest ones does not exceed $30 \mathrm{~min}$. The number of near-synchronised pairs totals 820 for the whole period of considered FTIR IWV measurements. Figure 4 depicts the IWV time series measured by the FTIR spectrometer at the St. Petersburg site in the period of 2009-2016. Relative differences between the M-type and Atype retrievals, as well as mean differences in absolute and relative units, and the correlation coefficient are shown in the bottom of Fig. 4. A dominant factor, which influences systematic differences between the A-type and M-type retrievals and does not have a pronounced seasonal or intra-annual dependence in relative units, is presumably the difference in spectroscopic line parameters and their accuracy in the two spectral regions (Rothman et al., 2009). 
Table 3. Instrumentation for IWV measurements at the St. Petersburg site.

\begin{tabular}{llll}
\hline Acronym & Instrumentation & Geometry & Comments \\
\hline FTIR & Bruker IFS-125HR & Solar tracking & Clear sky, 12 min duration \\
GPS & Novatel ProPak-V3 & 20-30 km horizontal resolution & Day and night, every 5 min \\
MW & RPG-HATPRO & Zenith viewing & Day and night, every 2 s \\
\hline
\end{tabular}

Figure 5 (left) illustrates the correlations between the Mtype and A-type retrievals. The slope demonstrates an overestimation of the M-type retrieval vs. A-type retrieval, with a factor of $1.09 \pm 0.02$. Buehler et al. (2012) obtained a slope of 1.06 by comparing FTIR measurements in nearly the same spectral regions for the Kiruna site (Sweden). Taking into account the uncertainties of both slopes, we may conclude that they are very close. Consequently, the assumption of $2 \%$ uncertainty for water vapour line intensities might be too optimistic and hence systematic errors might be larger than those indicated in Table 2. Currently, the adjustment of the $\mathrm{H}_{2}^{16} \mathrm{O}$ and $\mathrm{HD}^{16} \mathrm{O} \mathrm{M}$-type line parameters is based on a few aircraft profile measurements. Schneider et al. (2016) estimated the confidence of the $\mathrm{H}_{2}^{16} \mathrm{O}$ and $\mathrm{HD}^{16} \mathrm{O}$ line parameter adjustments to be about $10 \%$, meaning that the used line intensities might have an uncertainty of up to $10 \%$ (please be aware that the adjustment is aimed at $\left\{\mathrm{H}_{2}^{16} \mathrm{O}, \mathrm{HD}^{16} \mathrm{O} / \mathrm{H}_{2}^{16} \mathrm{O}\right\}$ pairs, and for the $\mathrm{H}_{2}^{16} \mathrm{O} / \mathrm{HD}^{16} \mathrm{O}$ ratios the confidence is better than $1.5 \%)$.

Figure 5 (right) depicts a histogram showing the relative frequency of absolute differences between the M-type and A-type retrievals: the distribution of differences is close to a lognormal probability distribution with location parameter of -0.06 and scale parameter of 0.80 . Almost a half of the differences are between 0.25 and $1.25 \mathrm{~mm}$.

Table 4 lists statistical characteristics of the M- and Atype comparison, depending on IWV values. Absolute differences increase with growing IWV values; relative differences slightly fall in the 8.6-9.9\% range. To harmonise IWV measurements of the A type and M type, we multiply IWV values of the A type by a factor of 1.09 and add an offset of $0.14 \mathrm{~mm}$ (and get the so-called $\mathrm{A}_{\text {corr }}$-type retrieval). As a result, the observed mean difference between the $M$ type and $A_{\text {corr }}$ type reduces to zero; the SD equals $0.42 \mathrm{~mm}(3 \%)$. The SD value is within the error margins of both types of retrievals (see Table 2), so we may conclude that both setups agree well. Therefore, for the following analysis and comparison with independent IWV measurements, we combine data sets of the $\mathrm{M}$ type and $\mathrm{A}_{\text {corr }}$ type to cover a more extended period.

Figure 6 shows an example of the use of the $A_{\text {corr-type }}$ retrieval in the harmonisation and analysis of the IWV diurnal cycle by the FTIR method. The number of separate measurements of one type may be insufficient to detect the strong variation of IWV in contrast with using a combination of both types of FTIR data. Figure 6 (right) demonstrates
Table 4. Statistics of synchronised IWV pairs (M type and A type) for different IWV values. Relative differences (mean \pm SD) in percent have been calculated with respect to the M-type values. $R$ is the correlation coefficient.

\begin{tabular}{lrrrr}
\hline \multirow{2}{*}{$\begin{array}{l}\text { IWV limits, } \\
\mathrm{mm}\end{array}$} & Matches & \multicolumn{2}{c}{ Difference } & $R$ \\
\cline { 3 - 4 } & & $\mathrm{mm}$ & $\%$ \\
\hline$<5$ & 165 & $0.3 \pm 0.1$ & $9.9 \pm 4.2$ & $0.99 \pm 0.01$ \\
$5-10$ & 164 & $0.7 \pm 0.3$ & $9.6 \pm 4.2$ & $0.98 \pm 0.02$ \\
$10-15$ & 146 & $1.2 \pm 0.5$ & $9.2 \pm 3.6$ & $0.95 \pm 0.03$ \\
$15-20$ & 172 & $1.5 \pm 0.4$ & $8.8 \pm 2.4$ & $0.95 \pm 0.02$ \\
$>20$ & 173 & $2.2 \pm 0.6$ & $8.6 \pm 2.3$ & $0.99 \pm 0.01$ \\
All & 820 & $1.2 \pm 0.8$ & $8.9 \pm 5.9$ & $0.999 \pm 0.002$ \\
\hline
\end{tabular}
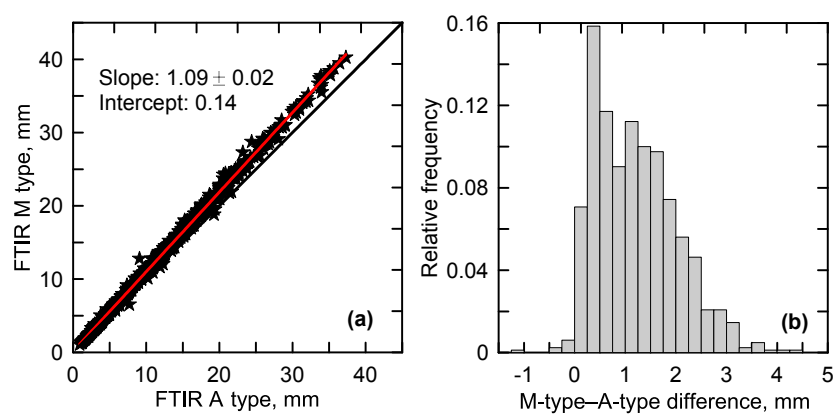

Figure 5. Correlations of synchronised IWV pairs: the M type vs. A type (a). Histogram of distribution of absolute differences: the M type minus A type (b). Red line is the linear regression line.

that, considering only an M-type retrieval, we miss decreasing IWV values by up to 9-10 mm (8:00-9:00 local time, UTC +3 h, 13 September 2016). At the same time, the correction of an A-type measurement helps to avoid "artificial" IWV variations caused by systematic differences between the retrieval types (Fig. 6, left).

\subsection{Simultaneous FTIR, MW, and GPS measurements}

Finally, we create three data sets of synchronised IWV measurements: FTIR (M type $+\mathrm{A}_{\text {corr }}$ type), MW (PHYS), and GPS for the period between August 2014 and October 2016. Figure 7 depicts results of the comparison as scatter plots showing correlation between the data pairs. Generally, different data sets correlate well, and the correlation coefficient is close to or larger than 0.99 for considered data pairs. However, the scatter of IWV values obtained from different tech- 

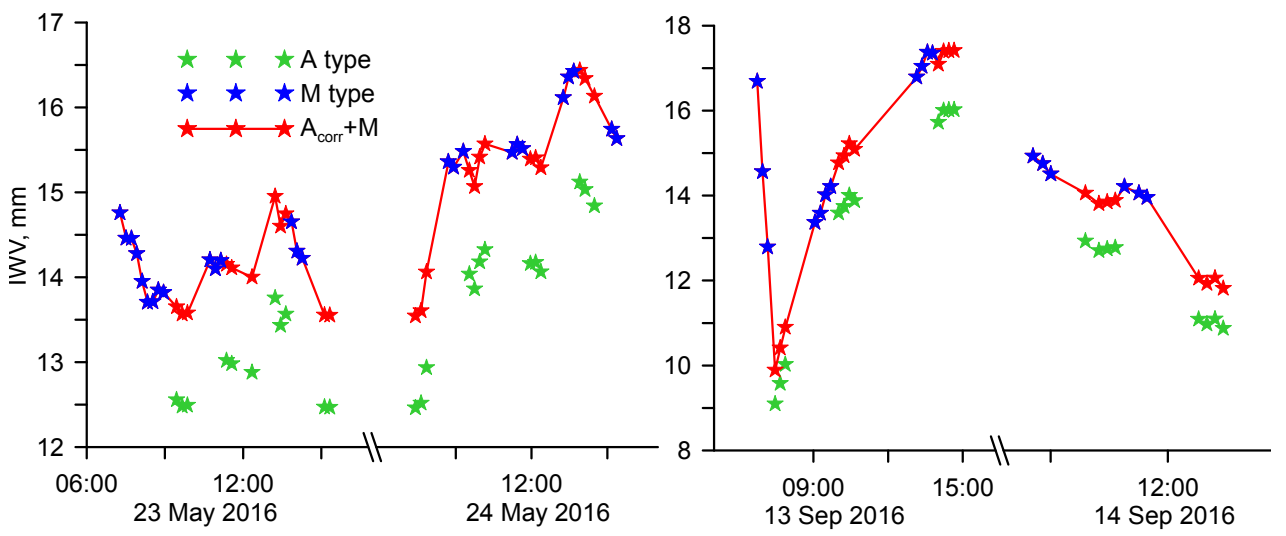

Figure 6. Diurnal variations of IWV content observed by the FTIR technique: the A-type retrieval (green stars), the M-type retrieval (blue stars), and the joint $\mathrm{A}_{\mathrm{corr}}$ and M-type retrieval (red line with stars).

niques depends on the IWV values themselves; the smaller the values, the greater the scatter. We observe the smallest IWV values obtained using the GPS technique (less than $1 \mathrm{~mm}$ ). The uncertainty of IWV GPS measurements equals $0.5-1.5 \mathrm{~mm}$ (see Sect. 2.3); thus, for dry atmosphere, the errors of the GPS technique might be larger than the measured IWV values (more than $100 \%$ ). At the same time, measurement errors of the MW technique are also larger for small IWV values due to the weakness of the $22 \mathrm{GHz}$ water vapour line (see Sect. 2.2). The best agreement between data pairs is observed for IWV values larger than 5-6 $\mathrm{mm}$. Even for these IWV values, FTIR measurements agree better with GPS and MW data than GPS and MW do with each other.

Table 5 presents results of the same comparison (mean differences and their SDs) of all IWV data pairs; i.e. it shows the biases and scatters between the different techniques. Since the GPS and MW techniques are less accurate for small IWV values, we single out two subsets depending on IWV quantity: less than $6 \mathrm{~mm}$ ("dry" subset) and larger than $6 \mathrm{~mm}$ ("wet" subset). FTIR and GPS measurements are in better agreement than other considered data pairs (the smallest scatter, the strongest correlation), whereas GPS and MW experience the largest scatter of differences with minimal bias. For all pairs, the smallest scatter in absolute and relative units is observed for the subset with IWV values greater than $6 \mathrm{~mm}$. A percentage scatter for the "dry" subset varies from 14.4 to $27.1 \%$, whereas for the "wet" subset it ranges from 4.6 to $7.1 \%$. The worst agreement is attributed to the GPS-MW pairs. These values of the scatter and correlation coefficient confirm that in dry atmosphere the GPS and MW techniques are less reliable for IWV measurements at the St. Petersburg site than the FTIR method.

Taking FTIR measurements as a reference, for the whole data set and for the "wet" subset, we observe an underestimation of GPS and MW data, with a larger dry bias for the latter. The same situation is seen for "dry" FTIR-GPS pairs. Particularly, this systematic discrepancy can be ex-
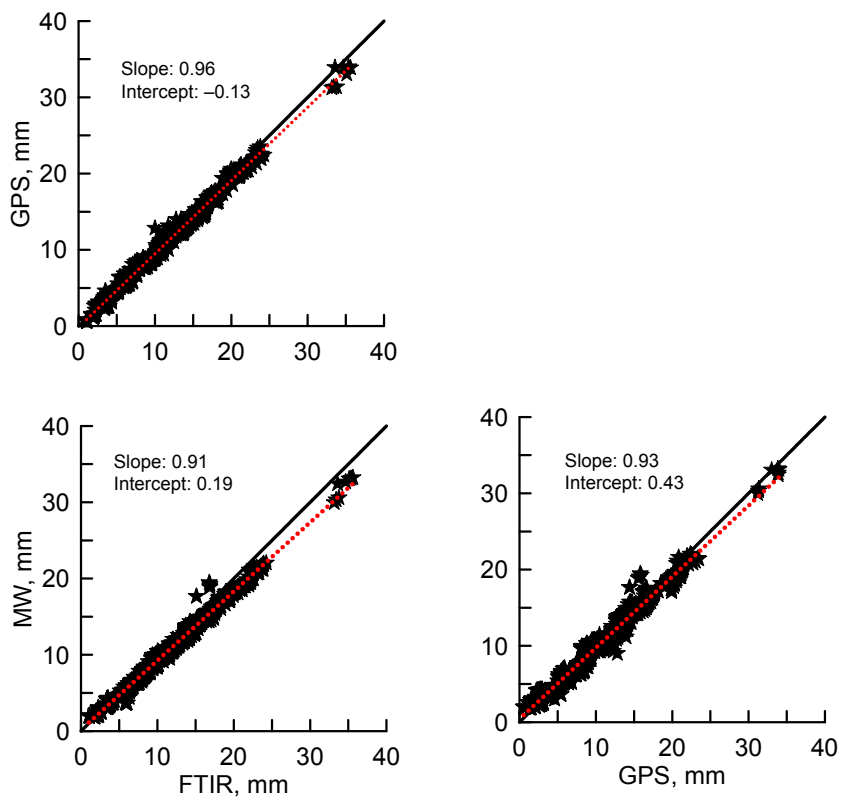

Figure 7. Correlation of IWV values measured by the FTIR, GPS, and MW techniques. Red dotted line is the linear regression line. The slope and intercept of the linear regression line are given in each panel.

plained by differences in instruments elevations above sea level (last column of Table 5) discussed at the beginning of Sect. 3. However, it is not the only reason for a systematic disagreement of IWV values, since the observed differences are larger than estimated for different elevations (Table 5). On the contrary, for the "dry" subset, the bias between the FTIR-MW and GPS-MW techniques is quite different: GPS measurements have a dry bias and FTIR measurements have no bias compared to MW data. This probably results from the increasing errors of MW measurements in a dry atmosphere. Excluding IWV differences due to the differences in 
Table 5. Statistics of differences (mean \pm SD) for all coincident IWV pairs depending on IWV values. Relative values correspond to the first instrument in pairs. $R$ is the correlation coefficient. The elevation bias is an estimated difference due to the difference in elevation of the instruments. The number of measurements total 819,161 , and 658 for $0-45,0-6$, and 6-45 mm data sets, respectively.

\begin{tabular}{|c|c|c|c|c|c|}
\hline \multirow[t]{2}{*}{ Pairs } & \multirow[t]{2}{*}{ IWV, mm } & \multicolumn{2}{|c|}{ Difference } & \multirow[t]{2}{*}{$R$} & \multirow[t]{2}{*}{ Elevation bias, $\mathrm{mm}$} \\
\hline & & $\mathrm{mm}$ & $\%$ & & \\
\hline FTIR-GPS & $\begin{array}{r}0-45 \\
<6 \\
>6\end{array}$ & $\begin{array}{l}0.59 \pm 0.62 \\
0.37 \pm 0.54 \\
0.64 \pm 0.63\end{array}$ & $\begin{array}{r}5.0 \pm 5.3 \\
9.9 \pm 14.4 \\
4.7 \pm 4.6\end{array}$ & $\begin{array}{r}0.995 \pm 0.003 \\
0.94 \pm 0.03 \\
0.993 \pm 0.005\end{array}$ & $0.1-0.4$ \\
\hline FTIR-MW & $\begin{array}{r}0-45 \\
<6 \\
>6\end{array}$ & $\begin{array}{l}0.91 \pm 0.86 \\
0.00 \pm 0.59 \\
1.13 \pm 0.77\end{array}$ & $\begin{array}{r}7.8 \pm 7.3 \\
1.3 \pm 15.7 \\
8.2 \pm 5.7\end{array}$ & $\begin{array}{r}0.994 \pm 0.004 \\
0.92 \pm 0.03 \\
0.991 \pm 0.005\end{array}$ & $0.2-0.5$ \\
\hline GPS-MW & $\begin{array}{r}0-45 \\
<6 \\
>6\end{array}$ & $\begin{array}{r}0.33 \pm 0.97 \\
-0.32 \pm 0.92 \\
0.49 \pm 0.92\end{array}$ & $\begin{array}{r}2.9 \pm 8.8 \\
-9.6 \pm 27.1 \\
3.7 \pm 7.1\end{array}$ & $\begin{array}{r}0.988 \pm 0.005 \\
0.81 \pm 0.05 \\
0.983 \pm 0.007\end{array}$ & $0.1-0.2$ \\
\hline
\end{tabular}

elevation of the considered instrumentation, we may reduce a wet bias of FTIR measurement with respect to GPS data by up to $0.2 \mathrm{~mm}$ for all observed IWV values. In this context, the biases in pairs with MW measurements depend on the IWV values themselves. Thus, for the whole data set and the "wet" data set, we may reduce a dry bias of MW measurements by up to $0.2-0.3$ and $0.4-0.6 \mathrm{~mm}$ in comparison with GPS and FTIR measurements, respectively. For small IWV values $(<6 \mathrm{~mm})$, the dry MW bias converts into a wet bias estimated as 0.2 and $0.4 \mathrm{~mm}$ compared to FTIR and GPS data.

\subsection{Empirical statistical assessment of IWV measurement errors}

Having three co-located methods for IWV retrieval at our disposal, we may empirically evaluate the uncertainty of individual methods. The individual estimate of the IWV value measured by method $\mathrm{A} x_{i}^{\mathrm{A}}$ can be expressed as $x_{i}^{\mathrm{A}}=x_{i, \text { true }}^{\mathrm{A}}+$ $M^{\mathrm{A}}+\sigma_{i}^{\mathrm{A}}$, where $x_{i, \text { true }}^{\mathrm{A}}$ is the true value of IWV, and $M^{\mathrm{A}}$ and $\sigma_{i}^{\mathrm{A}}$ are the systematic and statistical errors, respectively. Taking into account spatial $\left(\sigma^{\text {space }}\right)$ and temporal $\left(\sigma^{\text {time }}\right)$ misalignments of the two types of measurements (A and B) and assuming that statistical measurement errors are uncorrelated and have a zero mean, we can express the square of the observed $\mathrm{SD} \sigma^{\mathrm{A}-\mathrm{B}}$ as follows:

$\sigma^{\mathrm{A}-\mathrm{B}^{2}}=\overline{\sigma^{\mathrm{A}^{2}}}+\overline{\sigma^{\mathrm{B}^{2}}}+\overline{\sigma^{\text {time }^{2}}}+\overline{\sigma^{\text {space }^{2}}}$.

Since we inter-compare three near-synchronised data sets, we may assume that the temporal misalignment is equal to zero. As we have noted earlier, the FTIR spectrometer tracks the Sun, the MW radiometer has a zenith-viewing geometry, and GPS-receiver gets the information from different satellites providing a spatially averaged value of IWV. Therefore, the considered data triplets might have a spatial disagreement (Virolainen et al., 2016). However, we do not have two-dimensional maps of IWV fields at our disposal; thus, we cannot make a quantitative estimation of spatial disagreement. At the same time, we cannot select a statistically significant data set of dates with small IWV variability to analyse measurement uncertainties without spatial disagreement - we observe only 8 days in the considered period with $1 \%$ IWV variability during daytime. Therefore, we neglect this misalignment error, too. It means that we evaluate the upper bound of statistical measurement errors. Using Eq. (1) for each pair of data sets, we obtain a system of three linear equations from which we can derive the empirical statistical errors for each of the compared methods:

$$
\begin{aligned}
& \sigma_{\mathrm{FTIR}}=\sqrt{\frac{1}{2}\left(\sigma_{\mathrm{FTIR}-\mathrm{MW}}^{2}+\sigma_{\mathrm{FTIR}-\mathrm{GPS}}^{2}-\sigma_{\mathrm{GPS}-\mathrm{MW}}^{2}\right)}, \\
& \sigma_{\mathrm{MW}}=\sqrt{\frac{1}{2}\left(\sigma_{\mathrm{FTIR}-\mathrm{MW}}^{2}+\sigma_{\mathrm{GPS}-\mathrm{MW}}^{2}-\sigma_{\mathrm{FTIR}-\mathrm{GPS}}^{2}\right)}, \\
& \sigma_{\mathrm{GPS}}=\sqrt{\frac{1}{2}\left(\sigma_{\mathrm{GPS}-\mathrm{MW}}^{2}+\sigma_{\mathrm{FTIR}-\mathrm{GPS}}^{2}-\sigma_{\mathrm{FTIR}-\mathrm{MW}}^{2}\right)} .
\end{aligned}
$$

Using SD values from Table 5 in these equations, we get the statistical errors for the whole data set of compared IWV measurements (see the second column of Table 6). Since differences between considered measurements strongly depend on the IWV values (see Sect. 3.2), we tried to get the same estimates for the "dry" and "wet" subsets. The third column of Table 6 displays errors for the "wet" subset, while for the "dry" subset the system of Eq. (2) could not be solved presumably due to correlations of measurement errors of one or more instruments (MW, GPS) in dry atmosphere. Comparing the whole ( 819 triplets) and "wet" (658 triplets) data sets results, we see that errors significantly decrease only for the MW technique; along with the largest among other instruments error values, this confirms that MW measurements are less reliable in dry atmosphere.

For verification of the quality and accuracy of our estimates, we allocate one more data set - the so-called "MW 
Table 6. Empirical statistical errors of FTIR, GPS, and MW methods, as obtained from Eq. (2) for different data sets. Estimates are given in $\mathrm{mm}$ and in percent in parentheses.

\begin{tabular}{lccc}
\hline Data set & $0-45 \mathrm{~mm}$ & $6-45 \mathrm{~mm}$ & MW-stable \\
\hline FTIR & $0.29(1.6)$ & $0.27(1.3)$ & $0.31(1.9)$ \\
GPS & $0.55(5.1)$ & $0.57(4.4)$ & $0.52(4.6)$ \\
MW & $0.80(7.1)$ & $0.72(5.5)$ & $0.75(6.3)$ \\
\hline
\end{tabular}

stable" data set - for which we select measurements with variability of MW IWV values less than $2 \%$ for a $12 \mathrm{~min}$ averaging interval (717 data triplets). The estimates for the "MW stable" data set are shown in the fourth column of Table 6. All estimates from Table 6 allow us to assess the uncertainty of empirical statistical errors of IWV measurements at the St. Petersburg site as $0.29 \pm 0.02(1.6 \pm 0.3), 0.55 \pm 0.02$ $(4.7 \pm 0.4)$, and $0.76 \pm 0.04 \mathrm{~mm}(6.3 \pm 0.8 \%)$ for FTIR, GPS, and MW methods, respectively. Ionov et al. (2017) reported empirical statistical errors of $0.3 \mathrm{~mm}$ for the FTIR and MW methods and of $0.5 \mathrm{~mm}$ for GPS. The estimates for the FTIR and GPS techniques are nearly the same as in the current study, whereas for the MW method the error doubled. The difference between the two studies probably lies in different time samples and different types of interpretation of MW and FTIR spectra measurements.

Summing up the results of the IWV retrieval accuracy assessment, we may conclude that at the St. Petersburg site the FTIR and GPS techniques demonstrate more stable and consistent results than the MW technique.

\section{Discussion}

A great number of studies are devoted to the analysis of differences in water vapour FTIR measurements caused by differences in retrieval schemes: spectral microwindows, algorithms, a priori information, etc. (Schneider et al.,, 2010a, b; Schneider and Hase, 2009; Sussmann et al., 2009; Palm et al., 2010). Schneider et al. (2010b) compared the vertical profiles and total columns of $\mathrm{H}_{2} \mathrm{O}$ and HDO in 790-880, $1090-1330,2650-3180$, and $4560-4710 \mathrm{~cm}^{-1}$ spectral regions and showed that minimal statistical IWV measurement errors had been observed for the shortwave spectral interval $4560-4710 \mathrm{~cm}^{-1}$ due to the largest signal-to-noise ratio. The correction of spectral line parameters (line intensities and half widths) allowed reducing the systematic errors by up to $1 \%$ under the assumption of $1 \%$ uncertainty in line intensities (Schneider and Hase, 2009; Schneider et al., 2011). FTIR measurements underestimated radiosonde data systematically with differences of $0.1-0.5 \%$ for $2650-3180$ and $1090-1330 \mathrm{~cm}^{-1}$, and $2.2-2.4 \%$ for $4560-4710$ and 790 $880 \mathrm{~cm}^{-1}$ spectral regions (Schneider et al., 2010b). The SD of means amounted to approximately $7 \%$ in all cases. It is worth mentioning that IWV values measured in dif- ferent spectral regions are in good agreement. Schneider et al. (2010b) estimated the differences between FTIR IWV retrievals in $1090-1330$ and $2650-3180 \mathrm{~cm}^{-1}$ spectral regions to be $-1.0 \%$ with an SD of $1.2 \%$; Buehler et al. (2012) reported differences of $-3.4 \pm 7.3 \%$. We observe larger differences between the A-type and M-type schemes; the mean reaches $-8.9 \%$ (see Table 4 ). At the St. Petersburg site, IWV ranges from below $1 \mathrm{~mm}$ to more than $40 \mathrm{~mm}$, and both the mean difference and its SD are very consistent for different IWV values, indicating the high quality of IWV variability as obtained from both retrieval schemes. To extend the data set of FTIR measurements we correct the A-type retrievals in accordance with the M-type IWV values and use this joint data set for comparisons with independent measurements.

The spatial mismatch of compared data sets might significantly influence the results of the comparison. Semenov et al. (2015) coupled radiosonde data in Voejkovo with FTIR data at Peterhof; Berezin et al. (2016) did the same for MW data. Although correlations between measurements are higher than 0.96 , root mean square differences reached more than $20 \%$ for most of the collocated IWV data sets. The strong disagreement was mainly due to the natural spatial variability of IWV, taking into account the distance of $50 \mathrm{~km}$ between Peterhof (MW and FTIR instruments location) and Voejkovo (radiosondes launches). This variability reached approximately $13 \mathrm{~mm}$ during the day (Semenov et al., 2015). Even for monthly means of FTIR and radiosonde data (correlations higher than 0.99), the SD values reached approximately $11 \%$ (or $0.98 \mathrm{~mm}$ ). Excluding the days with strong IWV variability allowed reducing the mean differences between Voejkovo and Peterhof measurements by up to 3-4\% and the SD values by up to 12-14\%. Vogelmann et al. (2015) analysed spatial and temporal variations of water vapour by FTIR and lidar measurements and indicated their major role in discrepancies of different methods. They observed the strong spatial (at 1-4 km distance) and temporal (at 5-15 min interval) variations of up to $0.35 \mathrm{~mm}$ in summer. Steinke et al. (2015) also indicated spatial inhomogeneity of IWV on an $8-10 \mathrm{~km}$ scale as the reason for the $0.6 \mathrm{~mm}$ statistical differences between the different methods. The different viewing geometry of two nearby instruments (MW and FTIR) may also influence the results of inter-comparison, if observed air masses are at a distance of up to $20-25 \mathrm{~km}$ (Virolainen et al., 2016).

Table 7 presents examples of statistical results for the FTIR, MW, and GPS methods' inter-comparisons at a number of ground-based measurement stations. It is worth noting that direct comparisons of FTIR and MW IWV methods are very few. The MW radiometers used in inter-comparison campaigns (Buehler et al., 2012; Palm et al., 2010) were originally designed for observations of other atmospheric species; IWV was derived as a by-product, so the IWV retrieval scheme as well as its accuracy had not been optimised. Buehler et al. (2012) reported differences between MW and FTIR data sets at the Kiruna site (Sweden), which 
varied from $(-1.90 \pm 12.85) \%$ up to $(22.79 \pm 29.34) \%$, or from $(-0.20 \pm 0.92) \mathrm{mm}$ up to $(0.90 \pm 1.08) \mathrm{mm}$. Virolainen et al. (2016) showed that at the St. Petersburg site (Russia) MW measurements overestimated FTIR data by $0.29 \mathrm{~mm}$, not depending on season. The SD values varied from $0.24 \mathrm{~mm}$ (the dry season) to $0.54 \mathrm{~mm}$ (the wet season), amounting to $0.42 \mathrm{~mm}(4.1 \%)$ on average. In this study, differences between the two types of measurements are larger and have an opposite sign, amounting to $(0.85 \pm 0.87) \mathrm{mm}$ for FTIR vs. MW measurements. Such different results for the same site can be explained by different FTIR retrieval schemes: the A type in the earlier study (Virolainen et al., 2016) and the M type in this study. We have shown that both types of retrievals have systematic differences in IWV values of about $9 \%$, which can be easily corrected by a proposed simple harmonisation scheme.

The comparison between FTIR and GPS IWV data sets are discussed in several studies (Schneider et al., 2010a; Buehler et al., 2012; Mengistu et al., 2015). For both the Arctic and African site, GPS measurements overestimate FTIR data by $0.3-0.6 \mathrm{~mm}$. The SD of mean differences varies from 0.9 to $1.6 \mathrm{~mm}$. Our estimates at the St. Petersburg site demonstrate nearly the same results in the percent of underestimation of GPS vs. FTIR data as at the Izaña site (Canary islands), but larger in absolute values. This wet bias of FTIR measurements at the St. Petersburg site may come from the location of the GPS sensor, being $34 \mathrm{~m}$ higher than the FTIR spectrometer, which might be crucial under specific atmospheric conditions.

Finally, many studies are devoted to comparisons of GPS and MW IWV measurements (van Baelen et al., 2005; Memmo et al., 2005; Morland et al., 2006; Buehler et al., 2012; Steinke et al., 2015; Roman et al., 2016). Mean differences between the GPS and MW methods vary from -2.63 to $1.36 \mathrm{~mm}$ with SDs up to $3.69 \mathrm{~mm}$. Buehler et al. (2012) explained such significant differences by the influence of clouds and, probably, precipitation on the accuracy of the MW method. Ning et al. (2016) reported a detailed error analysis of the GPS method, indicating total errors of the GPS method to be equal to $0.6-0.7 \mathrm{~mm}$ for $23-33 \mathrm{~mm}$ of IWV values. Roman et al. (2016) presented a number of GPS and MW comparisons for IWV together with an intercomparison of independent GPS measurements at different measurement sites in the framework of the Atmospheric Radiation Measurement (ARM) program. In general, for all stations, GPS data overestimate MW measurements. For the ARM NSA (North Slope of Alaska) site, which is similar to the St. Petersburg site with respect to IWV variability range, systematic and random differences are much smaller than for the ARM TWP (tropical western Pacific) and SGP (southern Great Plains) stations. It is worth mentioning that for TWP site, the disagreement between the two GPS data sets reached $(0.8 \pm 3.1) \mathrm{mm}$. The differences between GPS and MW data at the St. Petersburg site are very similar to those reported by Roman et al. (2016) for the ARM NSA site.
Most of the differences presented in Table 7 (between FTIR, MW, and GPS IWV data pairs) are larger than observed in this study at the St. Petersburg site. The stringent spatial and temporal matching conditions applied here are the predominant reason, in our opinion, of good agreement between different methods for IWV measurements. Our figures demonstrate that with an accurate spatial and temporal matching of different types of IWV measurements their disagreements are close to the total measurement errors of individual methods.

\section{Summary}

The variety of requirements for IWV measurements in different fields of atmospheric science leads to the fact that there is no single unique method for IWV measurements that meets all requirements for accuracy, periodicity of measurements, horizontal resolution, etc. We describe three methods for IWV measurements (FTIR, MW, and GPS) available at the St. Petersburg site and compare these observations as near-synchronised data triplets.

We focus on the FTIR technique, checking whether it can be used as a reference for the MW and GPS methods under clear-sky conditions at the new NDACC site. We analyse the MUSICA IWV retrievals (M type) in comparison with the standard PROFFIT retrieval (A type) to enable the comparison with the results of previous studies. We evaluate averaged IWV measurement errors for the whole period of measurements (2009-2016) from the error matrix calculations and demonstrate that the M-type retrieval is slightly more accurate (systematic errors constitute 2.0 vs. $2.3 \%$ ) and precise (statistical errors make up 0.4 vs. $0.9 \%$ ) than the A-type retrieval. We observe the overestimation of the M-type retrieval vs. A-type retrieval with a scaling factor of $1.09 \pm 0.2$. The mean difference between the M-type and A-type retrievals amounts to $(1.2 \pm 0.8) \mathrm{mm}$ or $(8.9 \pm 5.9) \%$ and is mainly caused by the different spectroscopy in spectral regions related to the A-type and M-type setups. We harmonise the Mtype and A-type of IWV retrievals to increase the continuity of a series of IWV measurements using the FTIR method at the St. Petersburg site. The correction of A-type retrievals by a factor of 1.09 and by adding an offset of $0.14 \mathrm{~mm}$ allows reducing the differences between the M-type and A-type data to $(0.0 \pm 0.4) \mathrm{mm}$ or $(0 \pm 3) \%$, which is close to the IWV measurement errors of the FTIR method. We may recommend using such harmonisation at other sites equipped with high-resolution FTIR spectrometers.

We analyse in detail the FTIR, MW, and GPS techniques for IWV retrieval at the St. Petersburg site and allocate the data triplets of near-synchronised IWV measurements by all three methods. We show that FTIR and GPS measurements are in better agreement among all coincident pairs, whereas the GPS and MW methods experience the largest scatter of differences with minimal bias. The FTIR vs. The GPS meth- 
Table 7. Some results of IWV comparisons as reported by different authors. SD is the SD of mean differences; $R$ is the correlation coefficient.

\begin{tabular}{|c|c|c|c|c|c|}
\hline Study & Location & Matches & Bias, \% (mm) & $\mathrm{SD}, \%(\mathrm{~mm})$ & $R$ \\
\hline \multicolumn{6}{|l|}{ FTIR vs. MW } \\
\hline Buehler et al. (2012) & Kiruna, Sweden & $54-104$ & $\begin{array}{l}1.9--22.8 \\
(0.2--0.9)\end{array}$ & $\begin{array}{l}12.8-29.3 \\
(0.92-1.08)\end{array}$ & $0.933-0.986$ \\
\hline Virolainen et al. (2016) & Peterhof, Russia & 1254 & $-2.8(-0.29)$ & $4.1(0.42)$ & 0.998 \\
\hline $\begin{array}{l}\text { Current study } \\
\text { FTIR vs. GPS }\end{array}$ & Peterhof, Russia & 819 & $7.8(0.91)$ & $7.3(0.86)$ & 0.994 \\
\hline Buehler et al. (2012) & Kiruna, Sweden & $1329-1473$ & $\begin{array}{l}-7.4--10.9 \\
(-0.29--0.61)\end{array}$ & $\begin{array}{l}14.8-16.0 \\
(0.91-1.02)\end{array}$ & $0.982-0.983$ \\
\hline Schneider et al. (2010a) & Izaña, Spain & 112 & $5.36(0.09)$ & $19.5(0.73)$ & 0.958 \\
\hline Mengistu et al. (2015) & Addis Ababa, Ethiopia & 113 & $(-0.6)$ & $(1.6)$ & 0.92 \\
\hline $\begin{array}{l}\text { Current study } \\
\text { MW vs. GPS }\end{array}$ & Peterhof, Russia & 112 & $5.0(0.59)$ & $5.3(0.62)$ & 0.995 \\
\hline Van Baelen (2005) & Toulouse, France & $60-65$ & $(0.51-1.36)$ & $(2.60-3.21)$ & \\
\hline Memmo et al. (2005) & Elba, Italy & 1831 & $(0.01)$ & $(1.3)$ & 0.986 \\
\hline Morland et al. (2006), & Bern, Switzerland & & $(0.5)$ & $(1.0)$ & \\
\hline Buehler et al.,2012 & Kiruna, Sweden & $640-1385$ & $\begin{array}{l}10.2-12.9 \\
(0.45-0.93)\end{array}$ & $\begin{array}{l}27.0-28.6 \\
(1.75-2.66)\end{array}$ & $0.867-0.931$ \\
\hline Steinke et al. (2015) & Jülich, Germany & 3859 & $(0.18)$ & $(0.91)$ & 0.99 \\
\hline \multirow[t]{3}{*}{ Roman et al. (2016) } & See text for details & SGP-1055 & $(-1.04)$ & $(1.81)$ & 0.990 \\
\hline & & TWP-181 & $(-2.63)$ & $(3.69)$ & 0.961 \\
\hline & & NSA-8116 & $(-0.41)$ & $(0.79)$ & 0.999 \\
\hline Current study & Peterhof, Russia & 819 & $-2.9(-0.33)$ & $8.8(0.97)$ & 0.988 \\
\hline
\end{tabular}

ods agree within $(0.59 \pm 0.62) \mathrm{mm}$ or $(5.0 \pm 5.3) \%$, FTIR vs. MW within $(0.91 \pm 0.86) \mathrm{mm}$ or $(7.8 \pm 7.3) \%$, and finally GPS vs. MW within $(0.33 \pm 0.97) \mathrm{mm}$ or $(2.9 \pm 8.8) \%$ for the whole data set of synchronised triplets. It is worth mentioning that in a dry atmosphere (IWV values less than $6 \mathrm{~mm}$ ) the FTIR method is more reliable for IWV measurements than the MW or GPS techniques, for which the measurement errors are increasing with decreasing IWV values.

We observe an underestimation of the GPS and MW techniques with respect to FTIR data that occurs particularly due to differences in elevation of the considered instruments (GPS sensor is located $34 \mathrm{~m}$ higher than Bruker $125 \mathrm{HR}$ and $54 \mathrm{~m}$ higher than MW). Accounting for differences in IWV values due to the different elevation of instruments may significantly reduce systematic discrepancies between FTIR, GPS, and MW IWV measurements at the St. Petersburg site. Horizontal inhomogeneity of water vapour fields in the vicinity of the observing site might also result in the discrepancy of compared quantities due to different observational geometry, since the FTIR spectrometer tracks the Sun, while the MW radiometer has a zenith-viewing geometry, and GPSreceiver gets the information from different satellites providing a spatially averaged value of IWV.

Moreover, we empirically evaluate the upper bound of statistical measurement errors for all three methods and get the following estimates for clear-sky conditions at the St. Petersburg site: $0.29 \pm 0.02(1.6 \pm 0.3), 0.55 \pm 0.02(4.7 \pm 0.4)$, and $0.76 \pm 0.04 \mathrm{~mm}(6.3 \pm 0.8 \%)$ for the FTIR, GPS, and MW techniques, respectively. We demonstrate that the MW method is less consistent in IWV retrieval, especially under dry atmospheric conditions, presumably due to an operational instability of the MW radiometer RPG-HATPRO at the St. Petersburg site. Nevertheless, all three techniques agree well with each other and therefore are suitable for monitoring IWV values at the St. Petersburg site.

We compare our estimates with the published results and assume that accurate spatial and temporal matching of different IWV data is necessary for achieving a good agreement between measurements within the measurement errors of individual methods.

We conclude that the FTIR method is highly accurate but applicable only under clear-sky conditions; MW and GPS are all-weather methods, but they are less reliable in dry atmosphere. Therefore, we cannot recommend any instrument or technique as the best choice for the networks measuring IWV under a variety of atmospheric conditions. The different observation techniques complement each other rather than outperform each other. Based on our results, we propose the use of FTIR as a reference method under clear-sky conditions since it is reliable on all scales of IWV variability.

Data availability. All measurement data necessary to reproduce the comparison are available from the authors upon request (yana. virolainen@spbu.ru). 
Competing interests. The authors declare that they have no conflict of interest.

Special issue statement. This article is part of the special issue "Twenty-five years of operations of the Network for the Detection of Atmospheric Composition Change (NDACC) (AMT/ACP/ESSD inter-journal SI)". It is not associated with a conference.

Acknowledgements. The experimental part of the study has been supported by the Russian Foundation for Basic Research (grants number 15-05-07524 and 16-05-00681). The processing and analysis of the data have been performed with the financial support of the Russian Science Foundation (grant number 14-17-00096). The MUSICA FTIR retrievals have been developed in the framework of the MUSICA project, which has been funded by the European Research Council under the European Community's Seventh Framework Programme (FP7/2007-2013)/ERC grant agreement number 256961.

The Centre for Geo-Environmental Research and Modelling "GEOMODEL" of Saint Petersburg University provides the measurement facilities. J. W. Hannigan (NCAR, Boulder, CO, USA) kindly provides the station-specific WACCM data. We also acknowledge the availability of the NCEP data. The GPSmeasurements have been interpreted in accordance with the Russian Government Program of Competitive Growth of Kazan Federal University.

We acknowledge support by Deutsche Forschungsgemeinschaft and Open Access Publishing Fund of the Karlsruhe Institute of Technology.

Edited by: Hal Maring

Reviewed by: two anonymous referees

\section{References}

Askne, J. and Nordius, H.: Estimation of tropospheric delay for microwaves from surface weather data, Radio Sci., 22, 379-386, 1987

Barthlott, S., Schneider, M., Hase, F., Blumenstock, T., Kiel, M., Dubravica, D., García, O. E., Sepúlveda, E., Mengistu Tsidu, G., Takele Kenea, S., Grutter, M., Plaza-Medina, E. F., Stremme, W., Strong, K., Weaver, D., Palm, M., Warneke, T., Notholt, J., Mahieu, E., Servais, C., Jones, N., Griffith, D. W. T., Smale, D., and Robinson, J.: Tropospheric water vapour isotopologue data $\left(\mathrm{H}_{2}^{16} \mathrm{O}, \mathrm{H}_{2}^{18} \mathrm{O}\right.$, and $\left.\mathrm{HD}^{16} \mathrm{O}\right)$ as obtained from NDACC/FTIR solar absorption spectra, Earth Syst. Sci. Data, 9, 15-29, https://doi.org/10.5194/essd-9-15-2017, 2017.

Berezin, I. A., Timofeyev, Yu. M., Virolainen, Ya. A., and Volkova, K. A.: Comparison of ground-based microwave measurements of precipitable water vapor with radiosounding data, Atmos. Ocean. Opt., 29, 274-281, https://doi.org/10.1134/S1024856016030040, 2016.

Berezin, I. A., Timofeyev, Yu. M., Virolainen, Ya. A., Frantsuzova, I. S., Volkova, K. A., Poberovsky, A. V., Holben, B. N., Smirnov, A., and Slutsker, I: Error analysis of integrated water vapor measured by NIIMEL Photometer, Izv. Atmos. Ocean.
Phy.+, 53, 58-64, https://doi.org/10.1134/S0001433817010030, 2017.

Bevis, M., Businger, S., Herring, T., Rocken, C., Anthes, R., and Wave, R.: GPS meteorology: remote sensing of atmospheric water vapor using the global positioning system, J. Geophys. Res., 97, 787-801, https://doi.org/10.1029/92JD01517, 1992.

Buehler, S. A., Östman, S., Melsheimer, C., Holl, G., Eliasson, S., John, V. O., Blumenstock, T., Hase, F., Elgered, G., Raffalski, U., Nasuno, T., Satoh, M., Milz, M., and Mendrok, J.: A multiinstrument comparison of integrated water vapour measurements at a high latitude site, Atmos. Chem. Phys., 12, 10925-10943, https://doi.org/10.5194/acp-12-10925-2012, 2012.

Businger, S., Chiswell, S. R., Bevis, M., Duan, J., Anthes, R. A., Rocken, C., Ware, R. H., Exner, M., van Hove, T. T., and Solheim, F. S.: The promise of GPS in atmospheric monitoring, B. Am. Meteorol. Soc., 77, 5-18, https://doi.org/10.1175/15200477(1996)077<0005:TPOGIA>2.0.CO;2, 1996.

Dai, A., Meehl, G. A., Washington, W. M., Wigley, T. M. L., and Arblaster, J. A.: Ensemble simulation of twenty-first century climate changes: Business-as-usual vs. $\mathrm{CO}_{2}$ stabilization, B. Am. Meteorol. Soc., 82, 2377-2388, https://doi.org/10.1175/15200477(2001)082<2377:ESOTFC>2.3.CO;2, 2001.

Hase, F., Hannigan, J., Coffey, M., Goldman, A., Hopfner, M., Jones, N., Rinsland, C., and Wood, S.: Intercomparison of retrieval codes used for the analysis of high-resolution, groundbased FTIR measurements, J. Quant. Spectrosc. Ra., 87, 25-52, https://doi.org/10.1016/j.jqsrt.2003.12.008, 2004.

Hase, F.: Improved instrumental line shape monitoring for the ground-based, high-resolution FTIR spectrometers of the Network for the Detection of Atmospheric Composition Change, Atmos. Meas. Tech., 5, 603-610, https://doi.org/10.5194/amt-5603-2012, 2012.

Hegglin, M. I., Plummer, D. A., Shepherd, T. G., Scinocca, J. F., Anderson, J., Froidevaux, L., Funke, B., Hurst, D., Rozanov, A., Urban, J., von Clarmann, T., Walker, K. A., Wang, H. J., Tegtmeier, S., and Weigel, K.: Vertical structure of stratospheric water vapour trends derived from merged satellite data, Nat. Geosci., 7, 768-776, https://doi.org/10.1038/ngeo2236, 2014.

Ionov, D. V., Kalinnikov, V. V., Timofeyev, Y. M., Zaitsev, N. A., Virolainen, Y. A., Kostsov, V. S., and Poberovskii, A. V.: Comparison of radiophysical and optical infrared ground-based methods for measuring integrated content of atmospheric water vapor in atmosphere, Radiophys. Quant. El., 60, 300-308, https://doi.org/10.1007/s11141-017-9800-4, 2017.

IPCC: The Physical Science Basis, Contribution of Working Group I to the Fourth Assessment Report of the Intergovernmental Panel on Climate Change (IPCC 2007), edited by: Solomon, S., Qin, D., Manning, M., Chen, Z., Marquis, M., Averyt, R. B., Tignor, M., and Miller, H. L., Cambridge University Press, Cambridge, UK and New York, NY, USA, 2007.

Kalinnikov, V. V. and Khutorova, O. G.: Diurnal variations in integrated water vapor derived from a GPS ground network in the Volga-Ural region of Russia, Ann. Geophys., 35, 453-464, https://doi.org/10.5194/angeo-35-453-2017, 2017.

Kämpfer, N. (Ed.): Monitoring Atmospheric Water Vapour GroundBased Remote Sensing and Insitu Methods. Series: ISSI Scientific Report Series, 10 (VIII), Springer, New York, 2013.

Kiehl, J. T. and Trenberth, K. E.: Earth's annual global mean energy budget, B. Am. Meteorol. 
Soc., $\quad 78, \quad 197-208, \quad$ https://doi.org/10.1175/15200477(1997)078<0197:EAGMEB>2.0.CO, 1997.

Kostsov, V. S.: Retrieving cloudy atmosphere parameters from RPG-HATPRO radiometer data, Izv. Atmos. Ocean. Phy.+, 51, 156-166, https://doi.org/10.1134/S0001433815020085, 2015a.

Kostsov, V. S.: General approach to the formulation and solution of the multi-parameter inverse problems of atmospheric remote sensing with measurements and constraints of different types, Int. J. Remote Sens., 36, 2973-3004, https://doi.org/10.1080/01431161.2015.1054961, 2015b.

Kostsov, V. S., Timofeyev, Yu. M., Zaitsev, N. A., Poberovsky, A. V., and Osipov, S. I.: Application of the information approach to the analysis of two-year microwave observations of the atmosphere by the RPG-HATPRO radiometer at St. Petersburg University, Int. J. Remote Sens., 37, 3346-3364, https://doi.org/10.1080/01431161.2016.1199060, 2016.

Kouba, J.: A guide to using International GNSS Service (IGS) products, available at: http://kb.igs.org/hc/en-us/article_attachments/ 203088448/UsingIGSProductsVer21_cor.pdf (last access: 19 September 2017), 2015.

Makarova, M., Serdyukov, V., Arshinov, M., Voronin, B., Belan, B., Sinitsa, L., Polovtseva, E., Vasilchenko, S., and Kabanov, D.: First results of ground-based Fourier Transform Infrared Measurements of the $\mathrm{H}_{2} \mathrm{O}$ total column in the atmosphere over West Siberia, Int. J. Remote Sens., 35, 5637-5650, https://doi.org/10.1080/01431161.2014.945016, 2014.

Makarova, M. V., Poberovskii, A. V., Hase, F., Timofeyev, Yu. M., and Imhasin, K. K.: Determination of the characteristics of ground-based IR spectral instrumentation for environmental monitoring of the atmosphere, J. Appl. Spectrosc., 83, 429-436, https://doi.org/10.1007/s10812-016-0306-1, 2016.

Memmo, A., Fionda, E., Paolucci, T., Cimini, D., Ferretti, R., Bonafoni, D., and Ciotti, P.: Comparison of MM5 integrated water vapor with microwave radiometer, GPS, and radiosonde measurements, IEEE Geosci. Remote S., 43, 10501058, https://doi.org/10.1109/20.101109, 2005.

Mendes, V. B.: Modeling the neutral-atmospheric propagation delay in radiometric space techniques, UNB, New Brunswick, Canada, Tech. Report No. 199, 1999.

Mengistu Tsidu, G., Blumenstock, T., and Hase, F.: Observations of precipitable water vapour over complex topography of Ethiopia from ground-based GPS, FTIR, radiosonde and ERA-Interim reanalysis, Atmos. Meas. Tech., 8, 3277-3295, https://doi.org/10.5194/amt-8-3277-2015, 2015.

Mieruch, S., Noël, S., Bovensmann, H., and Burrows, J. P.: Analysis of global water vapour trends from satellite measurements in the visible spectral range, Atmos. Chem. Phys., 8, 491-504, https://doi.org/10.5194/acp-8-491-2008, 2008.

Morland, J., Deuber, B., Feist, D. G., Martin, L., Nyeki, S., Kämpfer, N., Mätzler, C., Jeannet, P., and Vuilleumier, L.: The STARTWAVE atmospheric water database, Atmos. Chem. Phys., 6, 2039-2056, https://doi.org/10.5194/acp-6-2039-2006, 2006.

Navas-Guzmán, F., Fernández-Gálvez, J., Granados-Muñoz, M. J., Guerrero-Rascado, J. L., Bravo-Aranda, J. A., and AladosArboledas, L.: Tropospheric water vapour and relative humidity profiles from lidar and microwave radiometry, Atmos. Meas. Tech., 7, 1201-1211, https://doi.org/10.5194/amt-7-1201-2014, 2014.
Niell, A. E.: Global mapping functions for the atmosphere delay at radio wavelengths, J. Geophys. Res.-Sol. Ea., 101, 3227-3246, 1996.

Nilsson, T. and Elgered, G.: Long-term trends in the atmospheric water vapor content estimated from groundbased GPS data, J. Geophys. Res.-Atmos., 113, D19101, https://doi.org/10.1029/2008JD010110, 2008.

Ning, T., Wang, J., Elgered, G., Dick, G., Wickert, J., Bradke, M., Sommer, M., Querel, R., and Smale, D.: The uncertainty of the atmospheric integrated water vapour estimated from GNSS observations, Atmos. Meas. Tech., 9, 79-92, https://doi.org/10.5194/amt-9-79-2016, 2016.

Oltmans, S. J., Vomel, H., Hofmann, D. J., Rosenlof, K. H., and Kley. D.: The increase in stratospheric water vapor from balloonborne frost-point hygrometer measurements at Washington, D. C., and Boulder, Colorado, Geophys. Res. Lett., 21 , 3453-3456, https://doi.org/10.1029/2000GL012133, 2000.

Pałm, M., Melsheimer, C., Noël, S., Heise, S., Notholt, J., Burrows, J., and Schrems, O.: Integrated water vapor above $\mathrm{Ny}$ Ålesund, Spitsbergen: a multi-sensor intercomparison, Atmos. Chem. Phys., 10, 1215-1226, https://doi.org/10.5194/acp-101215-2010, 2010.

Park, M., Randel, W. J., Kinnison, D. E., Emmons, L. K., Bernath, P. F., Walker, K. A., Boone, C. D., and Livesey, N. J.: Hydrocarbons in the upper troposphere and lower stratosphere observed from ACE-FTS and comparisons with WACCM, J. Geophys. Res.-Atmos., 118, 1964-1980, https://doi.org/10.1029/2012JD018327, 2013.

Perez-Ramirez, D., Whiteman, D. N., Smirnov, A., Lyamani, H., Holben, B. N., Pinker, R., Andrade, M., and AladosArboledas. L.: Evaluation of AERONET precipitable water vapor vs. microwave radiometry, GPS, and radiosondes at ARM Sites, J. Geophys. Res.-Atmos., 119, 9596-9613, https://doi.org/10.1002/2014JD021730, 2014.

Petit, G. and Luzum, B.: IERS Conventions, Bundesamt für Kartographie und Geodäsie, Frankfurt am Main, Germany, 2010.

Phillips, D.: A technique for the numerical solution of certain integral equations of the first kind, J. ACM, 9, 84-97, https://doi.org/10.1145/321105.321114, 1962.

Poberovsky, A. V.: High-resolution ground measurements of the IR spectra of solar radiation, Atmos. Ocean. Opt., 23, 161-163, https://doi.org/10.1134/S1024856010020132, 2010.

Reagan, J., Thome, K., Herman, B., Stone, R., Deluisi, J., and Snider, J.: A comparison of columnar water-vapor retrievals obtained with near-IR solar radiometer and microwave radiometer measurements, J. Appl. Meteorol., 34, 1384-1391, https://doi.org/10.1175/15200450(1995)034<1384:ACOCWV>2.0.CO;2, 1995.

Rodgers, C. D.: Inverse methods for atmospheric sounding, Theory and practice, Vol.2 of Series on Atmospheric, Oceanic and Planetary Physics, World Scientific, Singapore-New Jersey-LondonHong-Kong, 2000.

Roman, J., Knuteson, R., August, T., Hultberg, T., Ackerman, S., and Revercomb, H.: A global assessment of NASA AIRS v6 and EUMETSAT IASI v6 precipitable water vapor using groundbased GPS SuomiNet stations, J. Geophys. Res.-Atmos., 121, 8925-8948, https://doi.org/10.1002/2016JD024806, 2016.

Rothman, L. S., Gordon, I. E., Barbe, A., Benner, D. C., Bernath, P. F., Birk, M., Boudon, V., Brown, L. R., Campar- 
gue, A., Champion, J.-P., Chance, K., Coudert, L. H., Dana, V., Devi, V. M., Fally, S., Flaud, J.-M., Gamache, R. R., Goldman, A., Jacquemart, D.,. Kleiner, I., Lacome, N., Lafferty, W. J., Mandin, J.-Y., Massie, S. T., Mikhailenko, S. N., Miller, C. E., Moazzen-Ahmadi, N., Naumenko, O. V., Nikitin, A. V., Orphal, J., Perevalov, V. I., Perrin, A., Predoi-Cross, A., Rinsland, C. P., Rotger, M., Simeckova, M., Smith, M. A. H., Sung, K., Tashkun, S. A., Tennyson, J., Toth, R. A., Vandaele, A. C., and Vander Auwera, J.: The HITRAN 2008 molecular spectroscopic database, J. Quant. Spectrosc. Ra., 110, 533572, https://doi.org/10.1016/j.jqsrt.2009.02.013, 2009.

Saastamioinen, J.: Contributions to then theory atmospheric refraction, Part II. Refraction corrections in satellite Geodesy, B. Geod., 107, 13-34, 1973.

Schaer, S.: Mapping and predicting Earth's ionosphere using the Global Positioning System, Ph. D. dissertation, Astronomical Institute, University of Berne, Switzerland, 1999.

Schneider, M. and Hase, F.: Improving spectroscopic line parameters by means of atmospheric spectra: theory and example for water vapour and solar absorption spectra, J. Quant. Spectrosc. Ra., 110, 1825-1839, https://doi.org/10.1016/j.jqsrt.2009.04.011, 2009.

Schneider, M., Romero, P. M., Hase, F., Blumenstock, T., Cuevas, E., and Ramos, R.: Continuous quality assessment of atmospheric water vapour measurement techniques: FTIR, Cimel, MFRSR, GPS, and Vaisala RS92, Atmos. Meas. Tech., 3, 323338, https://doi.org/10.5194/amt-3-323-2010, 2010a.

Schneider, M., Toon, G. C., Blavier, J.-F., Hase, F., and Leblanc, T.: $\mathrm{H}_{2} \mathrm{O}$ and $\delta \mathrm{D}$ profiles remotely-sensed from ground in different spectral infrared regions, Atmos. Meas. Tech., 3, 1599-1613, https://doi.org/10.5194/amt-3-1599-2010, 2010b.

Schneider, M., Hase, F., Blavier, J.-F., Toon, G. C., and Leblanc, T.: An empirical study on the importance of a speed-dependent Voigt line shape model for tropospheric water vapor profile remote sensing, J. Quant. Spectrosc. Ra., 112, 465-474, https://doi.org/10.1016/j.jqsrt.2010.09.008, 2011.

Schneider, M., Wiegele, A., Barthlott, S., González, Y., Christner, E., Dyroff, C., García, O. E., Hase, F., Blumenstock, T., Sepúlveda, E., Mengistu Tsidu, G., Takele Kenea, S., Rodríguez, S., and Andrey, J.: Accomplishments of the MUSICA project to provide accurate, long-term, global and high-resolution observations of tropospheric $\left\{\mathrm{H}_{2} \mathrm{O}, \delta \mathrm{D}\right\}$ pairs - a review, Atmos. Meas. Tech., 9, 2845-2875, https://doi.org/10.5194/amt-9-2845-2016, 2016.

Semenov, A. O., Virolainen, Y. A., Timofeyev, Y. M., and Poberovsky, A. V.: Comparison of ground-based FTIR and radio sounding measurements of water vapor total content, Atmos. Ocean. Opt., 28, 121-125, https://doi.org/10.1134/S1024856015020116, 2015.
Steinke, S., Eikenberg, S., Löhnert, U., Dick, G., Klocke, D., Di Girolamo, P., and Crewell, S.: Assessment of smallscale integrated water vapour variability during HOPE, Atmos. Chem. Phys., 15, 2675-2692, https://doi.org/10.5194/acp-152675-2015, 2015.

Sussmann, R., Borsdorff, T., Rettinger, M., Camy-Peyret, C., Demoulin, P., Duchatelet, P., Mahieu, E., and Servais, C.: Technical Note: Harmonized retrieval of column-integrated atmospheric water vapor from the FTIR network - first examples for longterm records and station trends, Atmos. Chem. Phys., 9, 89878999, https://doi.org/10.5194/acp-9-8987-2009, 2009.

Tikhonov, A.: On the solution of incorrectly stated problems and a method of regularization, Dokl. Akad. Nauk SSSR+, 151, 501504, 1963.

Timofeyev, Y., Virolainen, Y., Makarova, M., Poberovsky, A., Polyakov, A., Ionov, D., Osipov, S., and Imhasin, H.: Groundbased spectroscopic measurements of atmospheric gas composition near Saint Petersburg (Russia), J. Mol. Spectrosc., 323, 2 14, https://doi.org/10.1016/j.jms.2015.12.007, 2016.

Trenberth, K. E., Fasullo, J., and Smith, L.: Trends and variability in column-integrated atmospheric water vapor, Clim. Dynam., 24, 741-758, https://doi.org/10.1007/s00382-005-0017-4, 2005.

Van Baelen, J., Aubagnac, J., and Dabas, A.: Comparison of nearreal time estimates of integrated water vapor derived with GPS, radiosondes, and microwave radiometer, J. Atmos. Ocean. Tech., 22, 201-210, https://doi.org/10.1175/JTECH-1697.1, 2005.

Virolainen, Y., Timofeyev, Y., Berezin, I., Poberovsky, A., Polyakov, A., Zaitsev, N., and Imhasin, H.: Atmospheric integrated water vapour measured by IR and MW techniques at the Peterhof site (Saint Petersburg, Russia), Int. J. Remote Sens., 37, 3771-3785, https://doi.org/10.1080/01431161.2016.1204025, 2016.

Vogelmann, H., Sussmann, R., Trickl, T., and Borsdorff, T.: Intercomparison of atmospheric water vapor soundings from the differential absorption lidar (DIAL) and the solar FTIR system on Mt. Zugspitze, Atmos. Meas. Tech., 4, 835-841, https://doi.org/10.5194/amt-4-835-2011, 2011.

Vogelmann, H., Sussmann, R., Trickl, T., and Reichert, A.: Spatiotemporal variability of water vapor investigated using lidar and FTIR vertical soundings above the Zugspitze, Atmos. Chem. Phys., 15, 3135-3148, https://doi.org/10.5194/acp-153135-2015, 2015.

Weaver, D., Strong, K., Schneider, M., Rowe, P. M., Sioris, C., Walker, K. A., Mariani, Z., Uttal, T., McElroy, C. T., Vömel, H., Spassiani, A., and Drummond, J. R.: Intercomparison of atmospheric water vapour measurements at a Canadian High Arctic site, Atmos. Meas. Tech., 10, 2851-2880, https://doi.org/10.5194/amt-10-2851-2017, 2017. 